\section{EEA and EFTA States coviD-19}

COVID-19 and the State Aid Rules - Update on ESA'S Work

The EFTA Surveillance Authority (ESA) monitors State aid granted by Iceland, Liechtenstein and Norway in order to facilitate a fair and open internal market in the European Economic Area. Mirroring the Commission's role for the 27 EU Member States, ESA enforces the general prohibition on State aid that applies in Iceland, Liechtenstein and Norway and is the sole competent authority to decide on whether a State intervention may be considered compatible. The State aid rules must be applied the same way all over the EEA, in the EU pillar as well as in the EFTA pillar.

In the same manner as the Commission, ESA has set up a dedicated task force to assist the Icelandic, Liechtenstein and Norwegian authorities with any queries they have or measures they would like to discuss. ESA has also expressed its firm commitment to the handling of any queries or proposed measures in a swift and efficient manner.
ESA has established a dedicated webpage at <http://www.eftasurv .int/state-aid/state-aid-rules-and -covid-19/> which contains fully updated information both on the State aid decisions adopted by ESA and the Commission as well as other useful information.

The State aid provisions from the EEA Agreement applicable to consider state interventions in the economy compatible are Article 61(2)(b) for compensation for damage caused by exceptional circumstances such as those caused by the COVID-19 outbreak, as well as Article 61(3)(b)-applicable in case of particularly severe economic situations, such as those resulting from the COVID-19 outbreak. Both provisions are identical in the wording to respectively Article 107(2)(b) and 107(3)(b) TFEU.

ESA usually issues its own guidelines for the assessment of compatibility of State aid in line with those adopted by the Commission. On this occasion, due to the extraordinary circumstances

DOI: 10.21552/estal/2020/1/17

* The authors are members of Clayton \& Segura State Aid Lawyers.

of the crisis, and the need to be extremely reactive, ESA has publicly announced on its website that it will not adopt its own framework but will apply the conditions set out by the Commission in the Temporary Framework when assessing the compatibility under Article 61(3)(b) of the EEA Agreement of State aid granted by the EEA EFTA States. There is an exception regarding the assessment of the compatibility of aid granted to the agricultural, fisheries and aquaculture sectors which mainly fall outside the scope of the EEA Agreement. This approach privileges the most efficient use of resources to quickly handle notifications and queries from Iceland, Liechtenstein and Norway to support the economy.

ESA has already adopted a State aid decision approving within 24 hours a guarantee scheme in Norway to ensure access to liquidity for micro, small and medium-sized enterprises (SMEs). The decision is based on the State aid Temporary Framework to support the economy in the context of the COVID-19 outbreak. This scheme enables the Norwegian authorities to provide public guarantees on investment and working capital loans granted to SMEs by credit institutions in order to meet immediate liquidity needs.

\title{
Marianne Clayton and
} Maria Segura* 